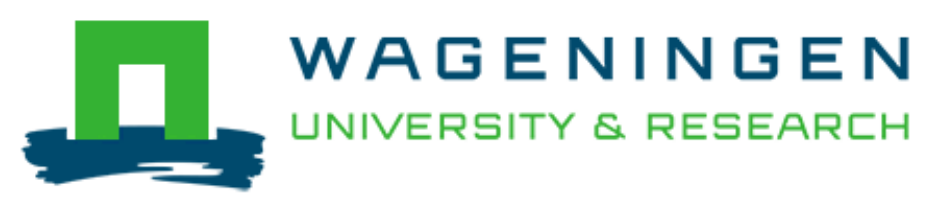

The Formation of GM-free and GM Coasean Clubs: Will They Form and If So How Much Can They Achieve?

Punt, M. J., \& Wesseler, J.

This article is made publically available in the institutional repository of Wageningen University and Research, under article 25fa of the Dutch Copyright Act, also known as the Amendment Taverne.

Article $25 \mathrm{fa}$ states that the author of a short scientific work funded either wholly or partially by Dutch public funds is entitled to make that work publicly available for no consideration following a reasonable period of time after the work was first published, provided that clear reference is made to the source of the first publication of the work.

For questions regarding the public availability of this article, please contact openscience.library@wur.nl.

Please cite this publication as follows:

Punt, M. J., \& Wesseler, J. (2018). The Formation of GM-free and GM Coasean Clubs: Will They Form and If So How Much Can They Achieve? Journal of Agricultural Economics, 69(2), 413-438. https://doi.org/10.1111/1477-9552.12235 


\title{
The Formation of GM-free and GM Coasean Clubs: Will They Form and If So How Much Can They Achieve?
}

\section{Maarten J. Punt and Justus Wesseler ${ }^{1}$}

(Original submitted January 2017, revision received April 2017, accepted June 2017.)

\begin{abstract}
The unintended presence of traces of genetically modified (GM) crops in the harvests of non-GM crops plays a prominent role in the debate over the coexistence of $G M$ and non-GM crops. One way to address the issue is the formation of GM-free or GM-only clubs. We model the decisions of individual farmers to cultivate either GM or non-GM crops and combine this with a game theoretic model of club formation to investigate the feasibility of such clubs. We consider two liability regimes: GM farmers are liable or they are not. We consider two benchmarks: Nash equilibrium without negotiations and the efficient allocation and compare those with partial co-operation through a Coasean club. We find that in both regimes a relatively large club can form but they are not always necessary to reach the efficient allocation. In fact, if farmers can freely decide under profit maximisation what to cultivate, they reach 95\% of an efficient allocation. This holds independent of the property rights system and provides strong support for coexistence policies based on ex-post liability such as in the US and Spain.
\end{abstract}

Keywords: Club formation; coalition formation; ex-post liability; game theory; GM coexistence.

JEL classifications: $Q 15, R 32, C 72$.

\section{Introduction}

Although the societal debate on genetically modified (GM) food and feed is far from settled (Smart et al., 2015), GM and non-GM crops are grown all over the world,

\footnotetext{
${ }^{1}$ Maarten Punt is in the Management and Economics of Resources and the Environment (MERE) Group, University of Southern Denmark, Denmark. E-mail: m.j.punt@ gmail.com for correspondence. Justus Wesseler is in the Agricultural Economics and Rural Policy Group, Wageningen University. The research leading to these results has received funding from the European Union's Seventh Framework Programme (FP7/2007-2013) under grant agreement no. KBBE -2011-5-289157. The authors thank anonymous referees for their helpful comments on an earlier draft.
} 
often close together. ${ }^{2}$ In the European Union and the United States, as well as many other states and regions of the world, there is an increasing call to guarantee both producers and consumers of agricultural products their freedom of choice. For example, in its recommendation on guidelines for coexistence the European Commission (2010) states: 'In principle, farmers should be able to cultivate the types of agricultural crops they choose - be it GM crops, conventional or organic crops'. In the same document the Commission also notes that: 'This possibility should be combined with the wish of some farmers and operators to ensure that their crops have the lowest possible presence of GMOs [genetically modified organisms]' (2010). Finally it also wants 'to provide European consumers with a choice between GM food and non-GM food' (2010). Similarly, the US Department of Agriculture (2015) states: 'Coexistence refers to the concurrent cultivation of conventional, organic, IP [identity preserved], and genetically engineered (GE) crops consistent with underlying consumer preferences and farmer choices. Farmers and others in the food and feed production chain have an important role in collaborating to make coexistence work, particularly in the areas of stewardship, contracting and attention to gene flow'.

In order to offer a choice between GM and non-GM food, both food types have to be supplied through segregated supply chains, with important implications. First, the crops produced with each system have to be separated throughout the supply chain to preserve their identity, and this separation starts at the farm level. Second, as consumers are unable to determine the origin of products, whether organic, conventional or GM, for themselves, the products have to be labelled to achieve successful product differentiation. The labelling itself can be either positive or negative and does not necessarily apply to all retail food products. Moreover, it is generally agreed that some consumers are willing to pay a price premium for non-GM products, although its size is debated (Scatasta et al., 2007). Clearly, if farmers are able to capture a part of this premium, they have an incentive to separate their crops. Cultivating GM crops, in contrast, often provides a cost advantage, yield advantage or both (Qaim, 2009), though with a possible price discount.

A problem, however, is that GM crops can accidentally cross-pollinate nearby nonGM varieties (adventitious presence). This generates an externality if these fields are owned by different farmers, since neighbours can no longer capture the price premium due to the adventitious presence. As pointed out by Coase (1960) this externality is reciprocal: the farmer cultivating GM crops (henceforth 'GM farmer') causes an external effect by planting GM crops and causing adventitious presence. One might, however, argue that the farmer cultivating non-GM crops (henceforth 'non-GM farmer') causes an external effect by planting a non-GM crop near a GM field, thus risking adventitious presence. ${ }^{3}$ Who has to bear the costs is governed by the property rights system that is in place. In Europe, GM farmers are generally liable for adventitious presence. In the US and Canada, the system is reversed and the problem mainly occurs for organic farming sold under certain private labels that require no

\footnotetext{
${ }^{2}$ We refer here to the definition of genetically modified organisms (GMOs) as defined by the European Commission, acknowledging that this definition is a political construct (Smart et al., 2015) and controversial from a natural science point of view (Herring, 2008). Also, sometimes we differentiate non-GM crops into conventional and organic.

${ }^{3}$ The situation described here can equally be thought of as a 'local commons setting' (Seabright, 1993). The common that is shared by a limited number of farmers is the pollen cloud and the farmers disagree about how much GM pollen this cloud is allowed to contain.
} 
adventitious presence. The US Department of Agriculture's organic label is process based and allows adventitious presence (Beckmann et al., 2011). Farmers can reduce the probability of adventitious presence by taking ex-ante coexistence measures such as buffer zones, isolation distances, and differences in sowing time. The costs of these measures, too, are borne by the liable party. Another way is the formation of voluntary clubs that pay other farmers in the landscape to cultivate a specific crop type (henceforth 'buy out').

Voluntary clubs initiated by farmers are of interest under both liability regimes. If GM farmers are not liable, as in the US and Canada, conventional or organic farmers could form a club and only cultivate conventional or organic crops. This would allow them to have access to the GM-free price premium, with a lower risk of losing it due to adventitious presence. Moreover, these clubs can reduce the costs of ex-ante coexistence measures. In the US, for example, organic farmers have dealt with these issues through co-operative agreements (see e.g. McEvoy, 2013). If, in contrast, GM farmers are liable for adventitious presence, as in Europe, they could form a club and agree among each other to cultivate only GM crops in their region. This would allow them to have access to the superior GM variety and reduce both the ex-ante costs of the coexistence measures and the expected costs of ex-post liability. ${ }^{4}$ An example of such a club in Portugal is described in Skevas et al. (2010). Moreover, if some of the farmers in that region still had an economic preference for non-GM crops, the cost savings introduced through the reduced ex-ante and expected ex-post costs could be used to buy these farmers out.

Under both liability regimes clubs reduce the ex-ante coexistence costs and mitigate the risks of adventitious presence of GM crops in non-GM fields. If GM farmers are non-liable, these clubs reduce potential price premium losses for non-GM farmers; if GM farmers are liable, clubs reduce the probability and amount of compensation payments for GM farmers. The problem for any club is that farmers outside the club enjoy the benefits, without bearing the costs - the free-riding problem - and it may prove difficult to form a club that can solve the externality problem completely. Clubs and the associated free-rider problem have received relatively little attention in the coexistence literature. To the best of our knowledge only Consmüller et al. (2012), Furtan et al. (2007) and Skevas et al. (2010) address clubs, but they do not consider strategic incentives and free-riding.

In this article we use the basic model of Beckmann and Wesseler (2007) to model individual farmers' decisions and extend it in two directions: (1) we make the model completely spatially explicit, and (2) we use it to investigate the possibility and efficiency of forming a GM-only or GM-free club in the landscape, accounting explicitly for the free-riding possibilities. The contribution of this article is therefore the consideration of strategic incentives in club formation in a spatially explicit model under both liability regimes. To the best of our knowledge we are also the first to investigate the potential problem of free-riding for GM-only and GM-free clubs.

Whether a GM-only or GM-free club is formed depends on the liability regime, as described above. Such a club is formed to mitigate problems of adventitious presence

\footnotetext{
${ }^{4} \mathrm{An}$ interesting feature in Europe is that there are GM-free regions too, even though GM farmers would be liable in case of adventitious presence. This suggests that either the farmers do not trust the legal system (e.g. because of the difficulty of proof or high up-front costs) or that these regions are formed out of other concerns, such as tourism or social pressure. The latter are some of the main reasons found in the analysis by Consmüller et al. (2012).
} 
and engages in Coasean bargaining, hence the name Coasean clubs. More formally we define Coasean clubs as: 'Clubs that seek to maximise the aggregate welfare of their members through a system of side payments towards those that have the property rights'. In our case the property rights refer to either the right to a GM-free harvest, or the right to cultivate GM crops. To be able to compare the two different property rights system, we assume a several liability regime, where a GM farmer on the one hand will be liable for adventitious presence according to his contribution, while a non-GM farmer will be 'liable' according to the adventitious presence he receives.

We proceed as follows: We first introduce the related literature. Next, we present a basic farmer decision model in two variants: when the GM farmer is not liable and when liable. We then consider two benchmarks: the Nash equilibrium without negotiations, and an efficient configuration. Then clubs are introduced, and we investigate their stability. Because the analytical results of club stability are inconclusive, we then conduct simulations to investigate the stability of clubs and what they achieve. The final section discusses the results and concludes the article.

\section{Related Literature}

Beckmann and Wesseler (2007) and Beckmann et al. (2011) addressed spatial incentives due to adventitious presence in general. They found that the boundary between choosing one crop type or another shifts depending on the division of property rights between GM and non-GM farmers, but has no effect on the final efficient allocation. They further show that this can be different if mandatory coexistence regulations are imposed. Beckmann and Wesseler (2007) do consider a number of technical measures to reduce the adventitious presence. They do not, however, consider explicit spatial measures or the possibility of club formation.

Groeneveld et al. (2013) studied the combination of spatially explicit measures and individual farmer's cultivation choices, and how these depend on the crop choices of their neighbours. They studied the incentives associated with a minimum distance requirement between GMO and non-GMO cultivation in the dairy industry and found that minimum distance requirements had a domino-effect, causing farmers to switch to other crop types because of the minimum distance requirement. However, Groeneveld et al. (2013) use a case study of Dutch dairy farms and therefore only consider one liability regime with mandatory minimum distance requirements and no club formation.

Moschini (2015) investigates a spatial setting, where the individual GM farmer or non-GM farmer must comply with coexistence regulations. Under the assumption of exogenous coexistence regulations he finds that sharing the costs equally between GM and non-GM farmers is the welfare maximising solution. Our contribution differs, as we start with the assumptions that specific coexistence policies are not in place and investigate, first, how close we get to the efficient allocation of land without imposing any additional regulation, and second, if the formation of clubs would be feasible, and if so, how much efficiency gain can be achieved.

GM-free clubs have been investigated by Furtan et al. (2007). In their model, organic farmers form a club, drawing up a binding agreement to cultivate only organic crops. Furthermore, the club buys out former GM farmers to establish a buffer zone of conventional cultivation around its land. Furtan et al. (2007) find that such clubs are feasible, in the sense that the captured premium is enough to 
compensate the former GM farmers. They do not, however, consider the individual incentives for farmers to join or exit such clubs. In contrast to Furtan et al. (2007) we take a strategic approach, that is, we look at the incentives for farmers to join a club, or to leave it once it has been formed. These incentives are investigated through the notion of cartel stability, first described by D'Aspremont et al. (1983) and later used in the environmental and resource agreements literature (see e.g. Dellink et al., 2008; Weikard, 2009; and Pintassilgo et al., 2010) and more recently to study local community resource management (Ansink and Bouma, 2013). This model is non-co-operative, but given that we deal with voluntary clubs we believe it is well suited.

\section{Model Description}

We assume farmers have a single field that they can plant with either a GM crop or a non-GM crop. We will assume that the non-GM crop commands a price premium over the GM crop, whereas the GM crop is cheaper to produce. More formally, we have a landscape that contains a set $N$ of farmers, denoted $i$.

The price a farmer $i \in N$ can claim given the quality of the crop is $p^{G}$ for the GM crop and $p^{C}$ for the non-GM crop. Although prices would in principle be farmer specific, due for instance to quality differences, we do not consider these differences in this model. Without loss of generality, we normalize the cost of producing GM crops to zero, and denote the additional costs of cultivating non-GM crops for farmer $i$ as $c_{i}$. This situation does not necessarily reflect reality everywhere, as a combination of ex-ante regulatory costs ${ }^{5}$ and additional seed costs may drive the costs of cultivating GM crops beyond those of conventional crops (Venus et al., 2017). In these situations, however, no-one would adopt GM crops.

If both costs and prices are equal across farmers, there would be no externality effect because all farmers either plant GM or non-GM crops, depending on the price premium and additional costs. However, often farmers do not face identical conditions, nor are their farms identical, due for instance to differences in landscape, land quality, managerial quality and machinery owned.

In the absence of adventitious presence, an individual farmer $i$ will choose non-GM crops if per unit of production:

$$
p^{C}-c_{i} \geq p^{G}
$$

and will choose GM crops otherwise. We further divide the set $N$ into two fixed subsets $\Phi$ and $X, \Phi \subseteq N, X \subseteq N$, defined through condition (1):

$$
\begin{aligned}
& \Phi=\left\{i \in N \mid \Delta p \geq c_{i}\right\} \\
& X=\left\{i \in N \mid \Delta p<c_{i}\right\},
\end{aligned}
$$

\footnotetext{
${ }^{5} \mathrm{We}$ do not model ex-ante regulatory costs explicitly because this would require assumptions about when and by whom these costs should be incurred, taking away the generality of the model. We acknowledge those costs can be substantial as Beckmann et al. (2010) have pointed out. These costs are implicitly considered in the cost difference between GM crops and non-GM crops, although we never allow them to exceed the additional costs of conventional crops. We investigate their effects later in the simulations.
} 
where $\Delta p=p^{C}-p^{G}$. The subsets $\Phi$ and $X$ are independent of the actual cultivation decisions by farmers, which may change because of the presence of the externality.

The externality is introduced in the basic model through a potential reduction in the price premium due to adventitious presence. If GM farmers are not liable, the costs of this potential reduction are borne by the non-GM farmers; if GM farmers are liable, they bear the costs. We further divide the set of farmers $N$ into two subsets, $F$ and $G$, which describe the cultivation decisions of the farmers. The set $F$ consists of $i \in N$ that choose to cultivate non-GM crops. The set $G$ consists of $j \in N$ that choose to cultivate GM crops. Given that GM crops are often the new trait or variety, if a farmer moves from set $F$ to set $G$, we will refer to such a move as 'switching', that is, switching from cultivating non-GM to GM crops. Moving from set $G$ to set $F$, in contrast, will be referred to as 'reverting'.

We denote $\alpha_{i j}$ as the probability that farmer $i$ that grows the non-GM crop is affected by farmer $j$. Equivalently, we can think of $\alpha_{i j}$ as the proportion of the harvest of farmer $i$ that is affected because farmer $j$ produces GM crops. In principle $\alpha_{i j}$ can be influenced by technical measures and is distance dependent. Moreover, it depends on the cultivation decisions $F$ and $G$ :

$$
\alpha_{i j}=\left\{\begin{array}{c}
0 \text { if } i \in G \text { or } j \in F \\
f\left(d_{i j}\right)
\end{array},\right.
$$

where $f\left(d_{i j}\right)$ is a monotonically decreasing function of the distance $d_{i j}$ between farmer $i$ and $j$. Then, given $\alpha_{i j}$ and the cultivation decisions, the probability that farmer $i$ is not affected is:

$$
A_{i}=\prod_{j \in N}\left(1-\alpha_{i j}\right) \forall i \in N
$$

The profits of farmers depend on the liability regime and their crop choice. We introduce the double superscripts $l$ to indicate that GM farmers are liable, and $n$ for when they are not.

When GM farmers are not liable for adventitious presence, the harvest of nearby non-GM farmers may have to be sold as GM crops, due to adventitious presence. Therefore, the expected profit of a non-GM and a GM farmer per unit of production are respectively:

$$
\begin{aligned}
& \pi_{i}^{C^{n}}=A_{i} p^{C}+\left(1-A_{i}\right) p^{G}-c_{i}=A_{i} \Delta p+p^{G}-c_{i} \forall i \in F, \\
& \pi_{j}^{G^{n}}=p^{G} \forall j \in G .
\end{aligned}
$$

When GM farmers are liable for adventitious presence, in principle they have to compensate all the non-GM farmers that they affect for the damage incurred. We assume several liability, i.e. among liable farmers everyone has to pay a share of the damage, proportional to the probability that they caused this damage (Koch, 2008).

The probability that farmer $i$ suffers from adventitious presence is $\left(1-A_{i}\right)$. The total expected compensation that GM farmer $j$ has to pay is then:

$$
\sum_{i \in N} \frac{\alpha_{i j}\left(1-A_{i}\right) \Delta p}{\sum_{k \in N} \alpha_{i k}}=D_{j} \Delta p
$$




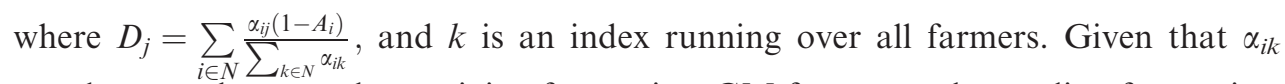
equals zero whenever the receiving farmer is a GM farmer or the sending farmer is a conventional farmer, the sum represents the sum of the probabilities of those GM farmers affecting farmer $i$. Consequently, the expected profits of a non-GM and a GM farmer per unit of production are respectively:

$$
\begin{aligned}
& \pi_{i}^{C^{l}}=p^{C}-c_{i}=\Delta p+p^{G}-c_{i} \forall i \in F \\
& \pi_{j}^{G^{l}}=p^{G}-D_{j} \Delta p \forall j \in G .
\end{aligned}
$$

We now consider two benchmarks: the Nash equilibrium when no negotiations take place and an efficient configuration. When no negotiations take place each farmer optimises their payoff, given the behaviour of others. They do not co-ordinate their cultivation choices and do not compensate each other to switch or revert. Equivalently, one can consider this as a case where transaction costs for bargaining are prohibitive. This situation is not meant as an actual description of reality but used as a reference point for the farmers that consider what would happen, if no-one makes side payments. As Beckmann et al. (2011) show, this results in an increase in the farm rents for the type of cultivation that gets the property rights, and given zero transaction costs for bargaining over the cultivation allocation of land between neighbours the farmers maximise the sum of their payoffs, and the cultivation decisions under both systems of property rights will be equivalent.

\subsection{The Nash equilibrium without negotiations}

In our model farmers choose either GM or non-GM crops; consequently, we are dealing with an integer problem. The marginal effect $M E$ from switching from non-GM to GM crops for farmer $k$ is therefore, from (5):

$$
M E=p^{G}-\left(A_{k} \Delta p+p^{G}-c_{k}\right)=c_{k}-A_{k} \Delta p .
$$

The marginal benefits of switching to GM are the incremental costs saved when farming GM, the marginal costs of switching are the expected realized price premium that is given up. Consequently, a farmer $k$ will switch from non-GM to GM if $c_{k}>A_{k} \Delta p$. In the Nash equilibrium no individual player has an incentive to deviate. Therefore, in the Nash equilibrium, when GM farmers are not liable the following must hold:

$$
\begin{gathered}
c_{i} \leq A_{i} \Delta p \forall i \in F^{*^{n}} \\
c_{j} \geq A_{j} \Delta p \forall j \in G^{*^{n}},
\end{gathered}
$$

where $F^{*^{n}}$ and $G^{*^{n}}$ denote the equilibrium sets with cultivation decisions when GM farmers are not liable. Online Appendix S1 establishes that equilibrium (9) always exists, but is not necessarily unique.

Since the set $\Phi=\left\{i \in N \mid \Delta p_{i} \geq c_{i}\right\}$, whereas $F^{*^{n}}=\left\{i \in N \mid A_{i} \Delta p_{i} \geq c_{i}\right\}$ and $0 \leq A_{i} \leq 1$, $F^{*^{n}}$ is a subset of $\Phi$. The presence of the externality requires that farmers account for the expected price premium rather than the price premium itself. In this Nash equilibrium, farmers cultivate non-GM crops only if the expected price premium is larger than the additional costs of non-GM crops. 
A feature of our model is that the marginal costs of switching go down the larger is the number of GM farmers. The reason is that the expected revenue from cultivating non-GM crops decreases with an increasing number of GM farmers. This also implies that some sort of a domino effect can be present: it may only pay for some farmers to switch once a number of others have switched.

If the property rights lie with the non-GM farmer, the marginal effect from switching for farmer $k$ is:

$$
\begin{aligned}
& M E=\left(p^{G}-D_{k} \Delta p\right)-\left(\Delta p+p^{G}-c_{k}\right) \\
& =c_{k}-\left(1+D_{k}\right) \Delta p .
\end{aligned}
$$

The marginal benefits of switching to GM are the incremental costs saved when farming GM, the marginal costs are the price premium that is given up plus the expected compensation paid to other non-GM farmers. In the Nash equilibrium no individual player has an incentive to deviate. Therefore, in the Nash equilibrium where the GM farmers are liable, the following must hold:

$$
\begin{gathered}
c_{i} \leq\left(1+D_{i}\right) \Delta p \forall i \in F^{*^{l}} \\
c_{j} \geq\left(1+D_{j}\right) \Delta p \forall j \in G^{*^{l}},
\end{gathered}
$$

where $F^{*^{l}}$ and $G^{*^{l}}$ denote the equilibrium cultivation decisions when GM farmers are liable. Online Appendix S1 establishes that equilibrium (11) always exists, though again, is not necessarily unique. Since the set $X=\left\{i \in N \mid \Delta p_{i}<c_{i}\right\}$, whereas $G^{*^{l}}=\left\{i \in N \mid\left(1+D_{j}\right) \Delta p_{i}<c_{i}\right\}$ and $D_{j} \geq 0 \forall i \in N, G^{*^{*}}$ is a subset of $X$. In this Nash equilibrium, farmers cultivate GM crops only if the additional costs of non-GM farming are larger than a multiple of the price premium. Obviously, under this property rights regime, switching is less attractive: not only does a switching farmer give up the full price premium, but in addition the farmer faces expected liability for damages of the non-GM neighbours. Thus, the larger the number of non-GM farmers is, the larger are the costs to the GM farmers.

Consequently, when there are no negotiations and everyone optimises their own payoff, an individual finds it generally more attractive to cultivate the crop type that has the property rights.

\subsection{The efficient configuration}

Consistently with Beckmann and Wesseler (2007) and Beckmann et al. (2011) we define an efficient allocation as the allocation where the sum of the profits of all farmers in a region is maximised. In that case all external effects are internalised and the final results are the same for both systems of property rights in terms of the configuration, although the distribution of benefits and costs over the individual farmers is different. When GM farmers are not liable, total profits $W$ are:

$$
W=\sum_{i \in F}\left(A_{i} \Delta p+p^{G}-c_{i}\right)+\sum_{j \in G} p^{G}
$$

The marginal effect $M E$ on total profit $W$ of farmer $k$ switching from non-GM to GM crops is: 


$$
M E=c_{k}-A_{k} \Delta p-\sum_{i \in N}\left(\alpha_{i k} A_{i} \Delta p\right) .
$$

The marginal benefits to society of a switching farmer consist of $c_{k}$, the original additional costs of farmer $k$ when cultivating non-GM crops. The marginal costs consist of the expected price premium lost by farmer $k$ plus the sum of the additional reduction in price premium of all the other non-GM farmers, which is the external effect. Although the last term in (13) is summed over the full set $N$, $\alpha_{i k}=0 \forall i \in G$, and hence the reduction in price premium only applies to non-GM farmers. In an efficient configuration, switching continues until the marginal costs exceed the marginal benefits, that is, in an efficient configuration the following holds:

$$
\begin{gathered}
c_{i} \leq A_{i} \Delta p+\sum_{l \in N}\left(\alpha_{l i} A_{l} \Delta p\right) \forall i \in F^{E} \\
c_{j} \geq A_{j} \Delta p+\sum_{l \in N}\left(\alpha_{l j} A_{l} \Delta p\right) \forall j \in G^{E},
\end{gathered}
$$

where $F^{E}$ and $G^{E}$ denote the efficient cultivation decisions.

According to the Coase theorem, in the absence of transaction costs, the efficient solution can be reached independently of the initial allocation of property rights. To see this, assume we allocate the property rights to the non-GM farmers and sum all profits:

$$
\begin{aligned}
W & =\sum_{i \in F}\left(\Delta p+p^{G}-c_{i}\right)+\sum_{j \in G}\left(p^{G}-D_{j} \Delta p\right) \\
& =\sum_{i \in F}\left(\Delta p+p^{G}-c_{i}\right)+\sum_{j \in G}\left(p^{G}\right)-\sum_{i \in N}\left(\left(1-A_{i}\right) \Delta p\right)
\end{aligned}
$$

Note that by (3) and (4) $A_{i}=1 \forall i \in G$. The corresponding marginal effect from a non-GM farmer $k$ switching to GM crops is:

$$
M E=c_{k}-A_{k} \Delta p-\sum_{i \in N} \alpha_{i k} A_{i} \Delta p
$$

Although the switching farmer is losing the full price premium when switching, the net effect is only the expected price premium because the rest is a transfer from the GM farmers. The last term is the increase in expected damages the GM farmers now have to pay because the probability of adventitious presence has increased for the remaining non-GM farmers. Because the marginal effect is the same, the optimum must also be the same. We show in online Appendix S1 that an efficient configuration is not necessarily privately optimal.

If all farmers could negotiate together and compensate each other through multilateral agreements at zero costs the externality could be internalised. However, many agents are involved, and in some cases agreements between multiple farmers are required for the compensation that is to be settled. This leads to a co-ordination problem because farmers have to co-ordinate who pays whom, and all farmers prefer the others to pay. This in turn leads to free-riding and the fully efficient allocation may not be achieved. In the next section we investigate whether partial co-operation through clubs is feasible. 


\section{The Formation of Coasean Clubs}

\subsection{Preliminaries}

If non-GM farmers are liable, a number of them may form a club, pool their profits and compensate a number of GM farmers for reversion to non-GM farming. This will increase their profits because it lowers the probability that their harvests will be affected by adventitious presence. These are the economic incentives to form a club. However, such a club also increases the profits of the non-GM farmers outside the club - there is an incentive to free-ride.

Similarly, if GM farmers are liable they may form a club, pool their profits, and compensate a number of non-GM farmers for switching to GM. ${ }^{6}$ This reduces the expected damages to be paid, but again this holds for GM farmers both inside and outside the club, with possible free-riding effects.

We assume that a single club can be formed among the players with the largest incentive to form a club. Thus if GM farmers are not liable, the potential club members are those farmers for whom $\Delta p>c_{i}$ holds (set $\Phi$ ), and if GM farmers are liable, the farmers for whom $\Delta p<c_{i}$ holds (set $X$ ). To keep the model simple we will assume open membership, that is, current members cannot bar entry of other farmers that want to join the club.

Club formation is modelled as a three-stage game following Barrett (2001). In the first stage the farmers in set $\Phi(X)$ announce their membership decisions. In the second stage the club members $S \subseteq \Phi(T \subseteq X)$ engage in Coasean bargaining with all members of set $X(\Phi)$, maximising the sum of the profits of the club members and the farmers in set $X(\Phi)$. In the third stage non-members pick their cultivation type independently. The game is solved through backward induction.

We introduce Coasean bargaining in the second stage of the game to abstract from the issue of modelling the actual bargaining process, as well as the order of offers, and the size of the side payments. We assume that farmers will simply switch or revert if the farmer in question gets at least the profit difference between GM and non-GM cultivation. The farmers addressed in this bargaining process have a dominant strategy to cultivate the other type, unless they are bought out, and hence there is no pre-emptive behaviour.

We define a partition function that assigns a payoff to every player outside the club as well as to the club as a whole. The stability of a club is investigated with cartel stability concepts originally derived by D'Aspremont et al. (1983). A club of $S$ members is internally stable if no member in the club can gain by leaving the club, that is,

$$
V_{k}(S) \geq V_{k}(S \backslash k) \forall k \in S,
$$

where $V_{k}(S)$ is the payoff to club member $k$ if in club $S$ and $V_{k}(S \backslash k)$ is the payoff to club member $k$ if not a club member, but the rest of the club stays intact. Similarly, a club is externally stable if no player outside the club can gain by joining the club:

\footnotetext{
${ }^{6}$ The incentives increase even more under joint and several liability, where one of the liable farmers has to pay the full damages and it becomes the obligation of defendants to sort out the share of payments, or joint liability, where just one of the liable farmers has to pay for the full damage and there is no obligation that other liable farmers have to contribute (Koch, 2008).
} 


$$
V_{o}(S)>V_{o}(S \cup o) \forall o \in N \backslash S,
$$

where $V_{o}(S \cup o)$ is the payoff to club member $o$ who joins club $S{ }^{7}$

Clearly internal and external stability depend on the sharing rule used within the club. We do not specify an explicit sharing rule but use the Claim Rights Condition (CRC) (Weikard, 2009). A club is internally stable if each member can be paid at least the amount received if leaving the club (the 'claim'). The remaining surplus can then be shared in any arbitrary way. Thus for the CRC to be satisfied we must have:

$$
\sum_{k \in S} V_{k}(S) \geq \sum_{k \in S} V_{k}(S \backslash k)
$$

Moreover, as Weikard (2009) shows, a club is externally stable if it cannot be enlarged to a club that satisfies the CRC. This guarantees the existence of at least one Nash equilibrium in the first stage, if the Nash equilibrium in the last stage is unique for each club that could form.

The use of the CRC and Coasean bargaining in the second stage also allows us to establish the following theorem:

Theorem When clubs are formed by the farmers in set $\Phi(\mathrm{X})$, the result of the CRC when all farmers in set $\mathrm{X}(\Phi)$ are considered club members is equivalent to the result of the CRC when only those farmers in set X $(\Phi)$ that are bought out are considered members and equivalent to the result of the CRC when none of the farmers of set $\mathrm{X}$ $(\Phi)$ are considered members.

Proof See online Appendix S1.

The intuition is that when farmers $S \subseteq \Phi$ form the club, the farmers of set $X$ always have the same claim: $p^{G}$, and they are only bought out if the sum of the gains of the $S$ farmers in the club outweighs the required compensation.

We use this feature within our simulations, but for clarity of the presentation we will not consider bought-out farmers as club members when we present our results, analytical or otherwise. Thus bought-out farmers or the wider set of farmers considered in Coasean bargaining are not considered or referred to as members. In contrast to the literature on environmental and fisheries agreements (e.g. Finus, 2003; Pintassilgo et al., 2010) we do, however, allow for a club size 1, that is, an individual farmer trying to negotiate with neighbours. ${ }^{8}$

\subsection{Analysis}

Non-GM clubs form when GM farmers are non-liable, hence the profit functions used for individual farmers are those in (5). If a number of non-GM farmers form a club $S \subseteq \Phi$, pool their profits, and buy out $H \subseteq X$ GM farmers, the club earns ${ }^{9}$ :

\footnotetext{
${ }^{7}$ The tie-breaking rule implies that if a member is indifferent between joining and not joining, the member will join, and is introduced following Weikard (2009).

${ }^{8}$ As a consequence in the literature on environmental agreements, there are $2^{|\Phi|}-|\Phi|\left(2^{|X|}-|X|\right)$ possible clubs; in our model there are $2^{|\Phi|}\left(2^{|\mathrm{X}|}\right)$ possible clubs.

${ }^{9}$ By Theorem 1 and the fact that we use Coasean bargaining we could have equally formulated the profits of the club as including the bought-out GM farmers as members, or even all GM farmers in set $X$. The stability results would have been the same.
} 


$$
\pi^{S}=\left(\sum_{i \in S}\left(\pi_{i}\right)\right)+\left(\sum_{h \in H}\left(A_{h} \Delta p-c_{h}\right)\right) .
$$

The first term of (20) is left unspecified because it is in principle possible that a member of $S$ cultivates GM crops. The last term is negative because $H \subseteq X$ and $X=\left\{i \in N \mid \Delta p<c_{i}\right\}$, and $0 \leq A_{i} \leq 1 \forall i \in N$. This term constitutes the compensation payments to the reverted GM farmers.

In the second stage of the game the club $S$ maximises:

$$
\max \left(\pi^{S}+\sum_{i \in X} \pi_{i}\right)
$$

For the remaining singletons the conditions in (9) still apply. As a result the Nash equilibrium in the last stage can be characterised as follows:

$$
\begin{aligned}
\forall i \in F^{*}{ }^{C C}\left\{\begin{array}{l}
\left\{c_{i} \leq A_{i} \Delta p\right\} \&\{i \in \Phi \backslash S\} \\
\text { or } \\
\left\{c_{i}-A_{i} \Delta p \leq \sum_{l \in S \cup X}\left(\alpha_{l i} A_{l} \Delta p+\sum_{k \in \Phi \backslash S} \alpha_{k i} A_{k} \Delta p\right)\right\} \&\{i \in(S \cup X)\}
\end{array}\right. \\
\forall j \in G^{*}{ }^{C C}\left\{\begin{array}{l}
\left\{c_{j} \geq A_{j} \Delta p\right\} \&\{j \in \Phi \backslash S\} \\
\text { or } \\
\left\{c_{j}-A_{j} \Delta p \geq \sum_{l \in S \cup X}\left(\alpha_{l j} A_{l} \Delta p+\sum_{k \in \Phi \backslash S} \alpha_{k i} A_{k} \Delta p\right)\right\} \&\{j \in S \cup X\}
\end{array}\right.
\end{aligned}
$$

where $F^{* C C}$ and $G^{*^{C C}}$ denote the Nash equilibrium decisions of the last stage when non-GM clubs are present. The intuition behind this equilibrium is as follows: Farmers that are not a member of club $S$ or targeted by club $S$ in Coasean bargaining still follow the conditions in (9). Members of $S$ or those targeted in Coasean bargaining will only cultivate non-GM crops if the compensation payment required not to cultivate GM crops is smaller than the marginal external effect of their GM cultivation on $S$ plus the effect of other farmers that will revert as a consequence of this buyout. The last effect is accounted for because the club moves first with its Coasean bargaining. The equilibria in (22) include the efficient solution and Nash equilibrium without negotiations as special cases for $S=\Phi$ and $S=\varnothing$, respectively.

Having established the equilibrium in the last stages, we move to the first stage. The stability of club $S$ depends on the outside option payoffs. The outside option payoff of the non-GM farmer $i$ is the payoff received if club $S \backslash i$ is formed. Summing all claims we find:

$$
\sum_{i \in S}\left(A_{i}^{\prime} \Delta p+p_{i}^{G}-c_{i}\right)
$$

where $A_{i}^{\prime} \Delta p$ denotes the expected price premium of farmer $i$ in the last stage of the game when the club $S \backslash i$ is formed, that is, when free-riding. If we deduct (23) from (20) we find that the claim rights condition holds if: 


$$
\sum_{i \in S}\left(\left(A_{i}-A_{i}^{\prime}\right) \Delta p\right)+\sum_{h \in H}\left(A_{h} \Delta p-c_{h}\right)>0
$$

In (24) the first term is the sum of the gains of the club members relative to being outside of the club, whereas the last term is the compensation payments made to the bought-out GM farmers. Recall that the last term of (24) is always negative. Thus, for a club to be stable, the sum of the gains from joining club $S$ of all members must be larger than the sum of compensation payments. Moreover, clubs are more likely to be stable if they achieve more than the clubs that form with one member less. In contrast, if a club without this farmer achieves exactly the same, there is no reason to join the club, as one will be obliged to be involved in the compensation payments without any additional gains.

If the GM farmers are liable, the payoff functions of the farmers change. If a club $T \subseteq X$ of $\mathrm{GM}$ farmers compensates $U \subseteq \Phi$ non-GM farmers, the club earns:

$$
\pi^{T}=\left(\sum_{u \in U}\left(c_{u}-\left(1+D_{u}\right) \Delta p\right)\right)+\left(\sum_{t \in T} \pi_{t}\right) .
$$

The first term of (25) is the total of compensation that has to be paid to farmers that the club buys out. Since $U \subseteq \Phi=\left\{i \in N \mid \Delta p \geq c_{i}\right\}$ and $D_{i} \geq 0 \forall i \in N$, this first term is negative. The last term is again unspecified, for reasons given above.

In the last stage the conditions in (11) still apply to the remaining singletons, whereas in the second stage the club maximises:

$$
\max \left(\pi^{T}+\sum_{i \in \Phi} \pi_{i}\right)
$$

Therefore, the equilibrium in the third stage can be characterised as follows:

$$
\begin{aligned}
\forall i \in F^{*^{G C}}\left\{\begin{array}{l}
\left.\left\{c_{i} \leq\left(1+D_{i}\right) \Delta p\right\} \&\{i \in X \backslash T)\right\} \\
\text { or } \\
\left\{\left(1+D_{i}\right) \Delta p-c_{i} \geq \sum_{t \in T \cup \Phi}\left(D_{t}-D_{t}^{\prime}\right) \Delta p\right\} \&\{i \in(T \cup \Phi)\}
\end{array}\right. \\
\forall j \in G^{* G C}\left\{\begin{array}{l}
\left\{c_{j} \geq\left(1+D_{j}\right) \Delta p\right\} \&\{j \in X \backslash T\} \\
\text { or } \\
\left\{\left(1+D_{j}\right) \Delta p-c_{j} \leq \sum_{t \in T \cup \Phi}\left(D_{t}-D_{t}^{\prime}\right) \Delta p\right\} \&\{j \in(T \cup \Phi)\}
\end{array}\right.
\end{aligned}
$$

where $D_{t}^{\prime}$ denotes the new damage payments for $t \in T \cup \Phi$, when the player switches. $F^{*^{G C}}$ and $G^{G^{G C}}$ denote the Nash equilibrium decisions of the last stage when GM clubs are present. The intuition behind this equilibrium is as follows: Farmers that are not a member of club $T$ or targeted by club $T$ in Coasean bargaining still follow the conditions in (11). Members of $T$ or those targeted in Coasean bargaining will only cultivate GM crops if the compensation payment required not to cultivate non-GM crops is smaller than the marginal external effect their non-GM cultivation has on $T$. This effect consists of four parts: the reduction in payments from $T$ to $j$ because $j$ no longer cultivates non-GM crops; the reduction in payments to other non-GM farmers 
because the total burden is shared by more GM farmers; an increase in payments because of the additional adventitious presence; and a decrease because of the other non-GM farmers that will revert as a result of the buying out (see online Appendix S1 for details). The last effect is accounted for because the club moves first with its Coasean bargaining. The equilibria in (22) include the efficient solution and Nash equilibrium without negotiations as special cases for $T=X$ and $T=\varnothing$, respectively.

Having established the equilibrium in the last stages, we move to the first stage. The stability of club $T$ depends on the outside option payoffs. The outside option payoff of the farmers in club $T$ is the payoff they get if a club is formed with the same GM farmers, but without them personally. Summing all claims we find:

$$
\sum_{j \in T}\left(p^{G}-D_{j}^{\prime} \Delta p\right)
$$

where $D_{j}^{\prime} \Delta p$ denotes the expected compensation to be paid by $j$ if $j$ leaves club $T$, that is, when free-riding. Deducting (28) from (25) we find that the claim rights condition holds if:

$$
\sum_{k \in U}\left(c_{k}-\left(1+D_{k}\right) \Delta p\right)+\sum_{j \in T}\left(D_{j}^{\prime}-D_{j}\right) \Delta p>0
$$

The first term of (29) is the total compensation that has to be paid to farmers that the club buys out; the second term is the reduction in the compensation that has to be paid to non-GM farmers if farmer $j$ joins the club. The first term is always negative, whereas the second term is positive if a larger club achieves more than any of the smaller ones, and zero otherwise. Thus, for a club to be stable, the sum of the gains from joining club $T$ in reducing the compensation payments to non-GM farmers must be larger than the sum of compensation payments within the club.

The intuition is similar to that for non-GM clubs. Clubs are more likely to be stable if they achieve more than smaller clubs; if not, there is no reason to join.

\subsection{Simulations}

Within the previous model, more precise results about what clubs would form and what they would achieve in efficiency terms can only be obtained through simulations. In this section we investigate the Nash equilibrium without negotiation, the efficient configuration, that is, we select among all possible allocations the one that generates the largest sum of profits over all farms and clubs in a grid ${ }^{10}$ for both liability regimes. We assume that the individual probability of adventitious presence $\alpha_{i j}$ is a declining function of Euclidian distance between farmer $i$ and $j$. The parameter values are given in Table 1.

In online Appendix S2 we report the individual probabilities $\alpha_{i j}$ resulting from our distance function, as well as the frequency distribution of the overall adventitious presence $\left(1-A_{i}\right)$ over all possible configurations and farmers. The price of GM crops is based on the average price of maize in European countries in the period 2000-2005 (Eurostat). The price premium for certified non-GM soybeans has been relatively

\footnotetext{
${ }^{10} \mathrm{We}$ show results for a line with eight farmers as well in online Appendix S3.
} 
Table 1

Parameter values in the draws

\begin{tabular}{ll}
\hline Parameter & Value \\
\hline$p^{C}$ & $110(€ /$ tonne $)$ \\
$p^{G}$ & $100(€ /$ tonne $)$ \\
$c_{i}$ & Integer $\in[1,25](€ /$ tonne $)$ \\
$\alpha_{i j}$ & $\mathrm{e}^{-1.5 \text { (distance) }}$ \\
\hline
\end{tabular}

stable at 10\% (U. Felhölter, feed retailer, cited in Wesseler, 2014). For many other crops it has been even less (Foster, 2010). Therefore, we have assumed a price of nonGM crops that is $10 \%$ higher than that of GM crops. The range of additional costs and the distance function were chosen such that both types of cultivation would be practiced in the draws.

Following Pintassilgo et al. (2010) we investigate three important parameters: the stability likelihood $\theta$, the efficiency gain $\Omega$ (called 'social gain' in Pintassilgo et al.), ${ }^{11}$ and closing the gap $\Gamma$. Stability likelihood is the probability that a random $m$ size club is stable and is estimated through the sampling proportion:

$$
\widehat{\theta}_{m}=\frac{Y}{n_{d r w}}
$$

where $Y$ is the number of times a randomly chosen $m$-size club was stable and $n_{d r w}$ is the total number of draws for a fixed number of players.

The efficiency gain is an index measuring how much is to be gained from an efficient allocation compared to the Nash equilibrium without negotiations and is defined as:

$$
\Omega=\frac{W-\sum_{i \in N} \pi_{i}^{\text {Nash }}}{W} \times 100
$$

where $W$ is the sum of profits in an efficient configuration, as before, and $\pi_{i}^{\text {Nash }}$ is the profit of farmer $i$ in the Nash equilibrium without negotiations. $\bar{\Omega}$ is the arithmetic mean over all draws. Similarly, closing the gap is an index measuring what proportion of the efficiency gain clubs on average realise. For a stable club $S^{*}$ it is defined as:

$$
\Gamma\left(S^{*}\right)=\frac{\left(\Pi\left(S^{*}\right)+\sum_{i \in N \backslash S} \pi_{i}^{S}\right)-\sum_{i \in N} \pi_{i}^{\text {Nash }}}{W-\sum_{i \in N} \pi_{i}^{\text {Nash }}}
$$

with $\Pi\left(S^{*}\right)$ the profits of club $S^{*}$ and $\pi_{i}^{S}$ the profits of farmers outside of club $S^{*} . \check{\Gamma}$ is the arithmetic mean of all $\Gamma\left(S^{*}\right)$ of stable clubs in one draw and $\bar{\Gamma}$ is the arithmetic mean of all $\check{\Gamma}$ in the number of draws under consideration.

Following Pintassilgo et al. (2010), we originally opted for 50,000 draws to investigate the stability of clubs, which would have resulted in a standard deviation for the stability likelihood of maximal 0.004 . However, because a number of draws had

\footnotetext{
${ }^{11}$ We refrain from calling this social gain because we do not model consumer effects and transaction costs.
} 
multiple Nash equilibria in the last stage of the game, we increased the number of draws by $10 \%$, for a total of 55,000 draws.

The draws consisted of random cost vectors out of the range specified in Table 1. We conducted 55,000 draws for a grid of four by three farmers. Because we sample the costs for all the individual farmers at the same time, the maximum number of club players, that is, the number of players in sets $\Phi$ and $X$, within a draw is determined by the sampling procedure. Cost vectors were drawn such that there were always a minimum of two farmers with $\Delta p-c_{i} \geq 0$ and two farmers with $\Delta p-c_{i}<0$. In this way the sets $\Phi$ and $X$ always contained at least two members that could form clubs. Farmers that had $c_{i}=10$ were assumed to be part of set $\Phi$.

Runs were discarded if a Nash equilibrium in the last stage of the game was not unique. The reason is that in this case there is a selection problem: it is unclear which one of these multiple equilibria is to be used as a reference when the internal stability of a club is checked. ${ }^{12}$ In addition, if there are multiple equilibria in the Nash equilibrium without negotiations, which is a last-stage Nash equilibrium as well, the indices Efficiency Gain and Closing the Gap are not well defined. The problem of multiple equilibria occurs in $4 \%$ of the draws, except for the grid when GM farmers are liable, where it occurs in $20 \%$.

This procedure resulted in a very low number of draws for $|\Phi|=10$ and $|X|=2$. Therefore, we ran an additional 2,000 draws for both situations, using a different sampling procedure. In this procedure, we drew cost vectors such that, although randomised, the sample always contained 10 farmers for whom $\Delta p-c_{i}>0$, resulting in the desired $|\Phi|=10$ and $|X|=2$. Their location within the $4 \times 3$ grid was random. The results of the simulation remain qualitatively the same. The reason for the small number of draws with $|\Phi|=10$ and $|X|=2$ is twofold: the probability of drawing a vector with $|\Phi|=10$ and $|X|=2$ is low; and draws with $|\Phi|=10$ and GM farmers not liable face multiple equilibria in roughly $50 \%$ of the draws.

In Tables 2 and 3 we report the stability likelihood as well as the two indices from our simulation results. Examples of typical draws are shown in Figure 1. Figure 1 shows that club members sometimes cultivate the crop type that their club addresses in Coasean bargaining, for example the members of a GM-free club cultivate GM in Figure 1, example 1. This is caused by assumptions (2) and (18). Assumption (2) implies that potential club members are defined in the absence of the externality. These farmers represent farmers that are indifferent between joining and not joining. Our tie-breaking rule in (18) implies that farmers will join a club in that case.

From the tables we see that the efficiency gain is in general very small, almost always below $1 \%$. The main reason for this is the relatively small price premium for non-GM crops. As a sensitivity analysis we use price premiums of $15 \%$. Price premiums of $15 \%$ are rare but are in principle possible for high value crops and seeds. The results are shown in online Appendix S4. They are qualitatively the same. The main difference is that when GM farmers are not liable, smaller clubs become more stable and large clubs become less stable. When GM farmers are liable, smaller clubs become less stable and large clubs become more stable, although the effect is less pronounced,

\footnotetext{
${ }^{12}$ Alternative ways of dealing with multiple equilibria are checking whether the payoff for players in the club is larger than the best payoff of the multiple Nash equilibria (Olieman and Hendrix, 2006), or ensuring a dominant strategy (Dellink et al., 2008). Dominant strategies are not present for all players in our game, and instead of making an additional assumption we opted for discarding the draw altogether.
} 


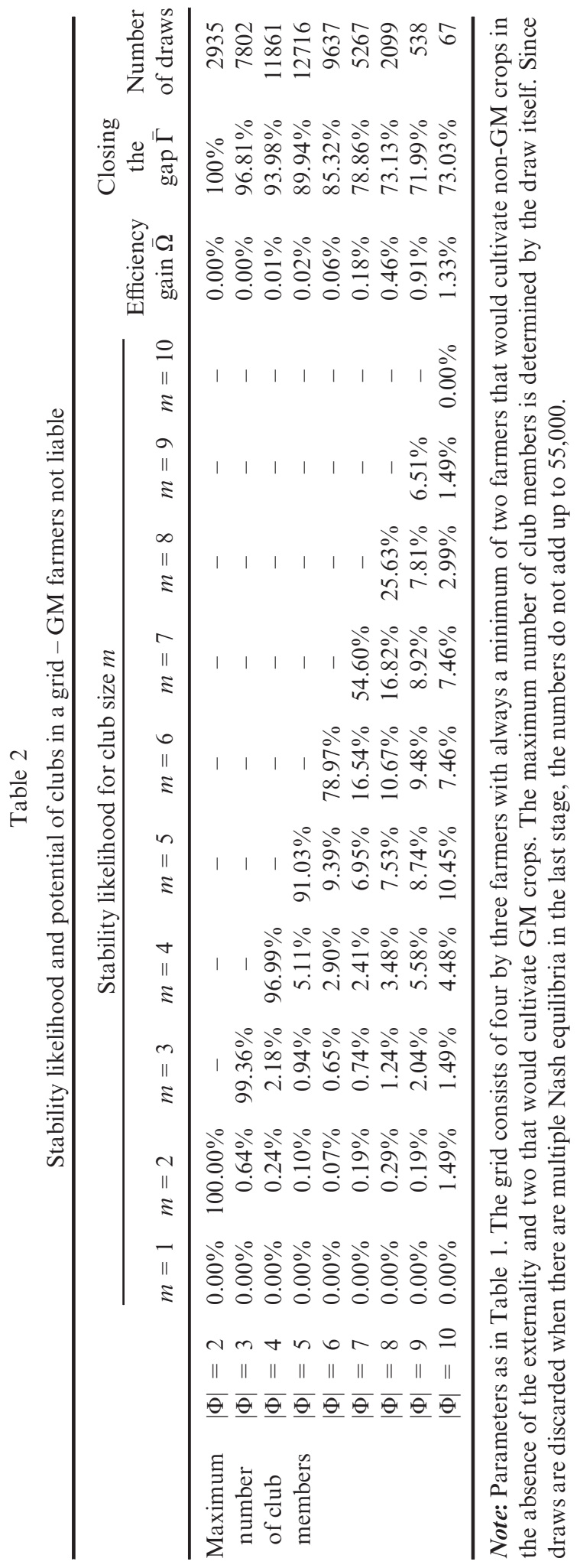




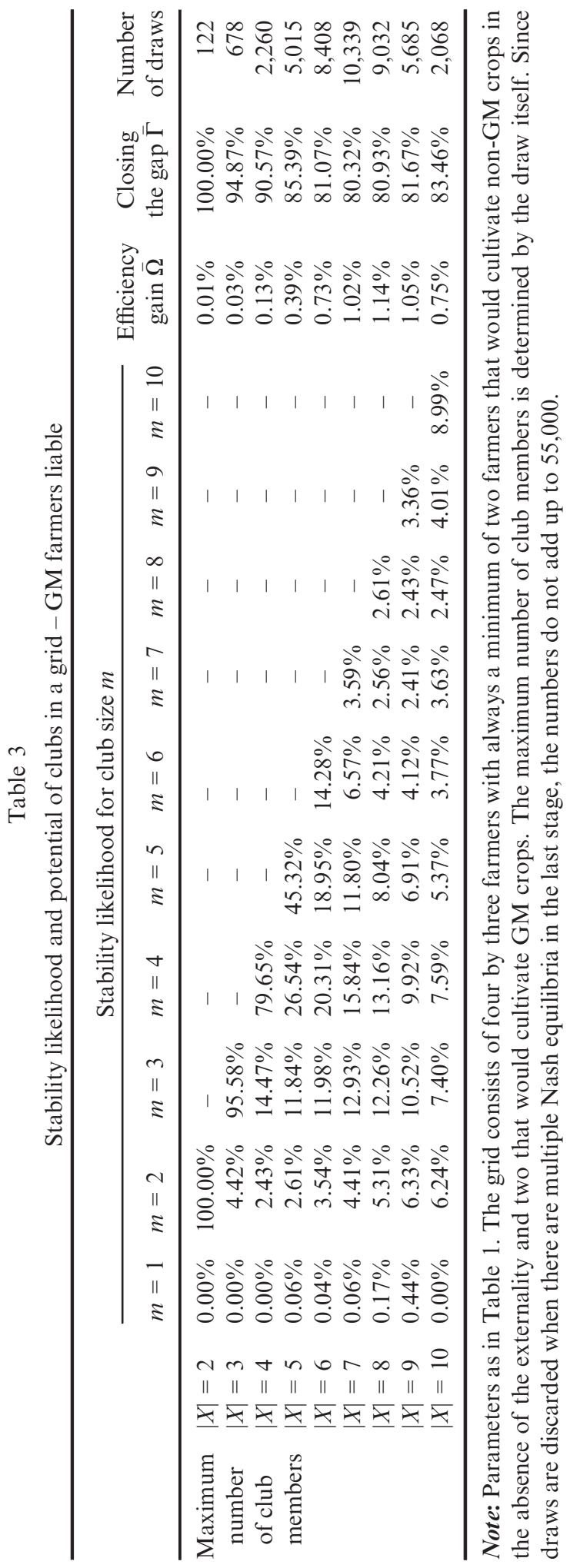




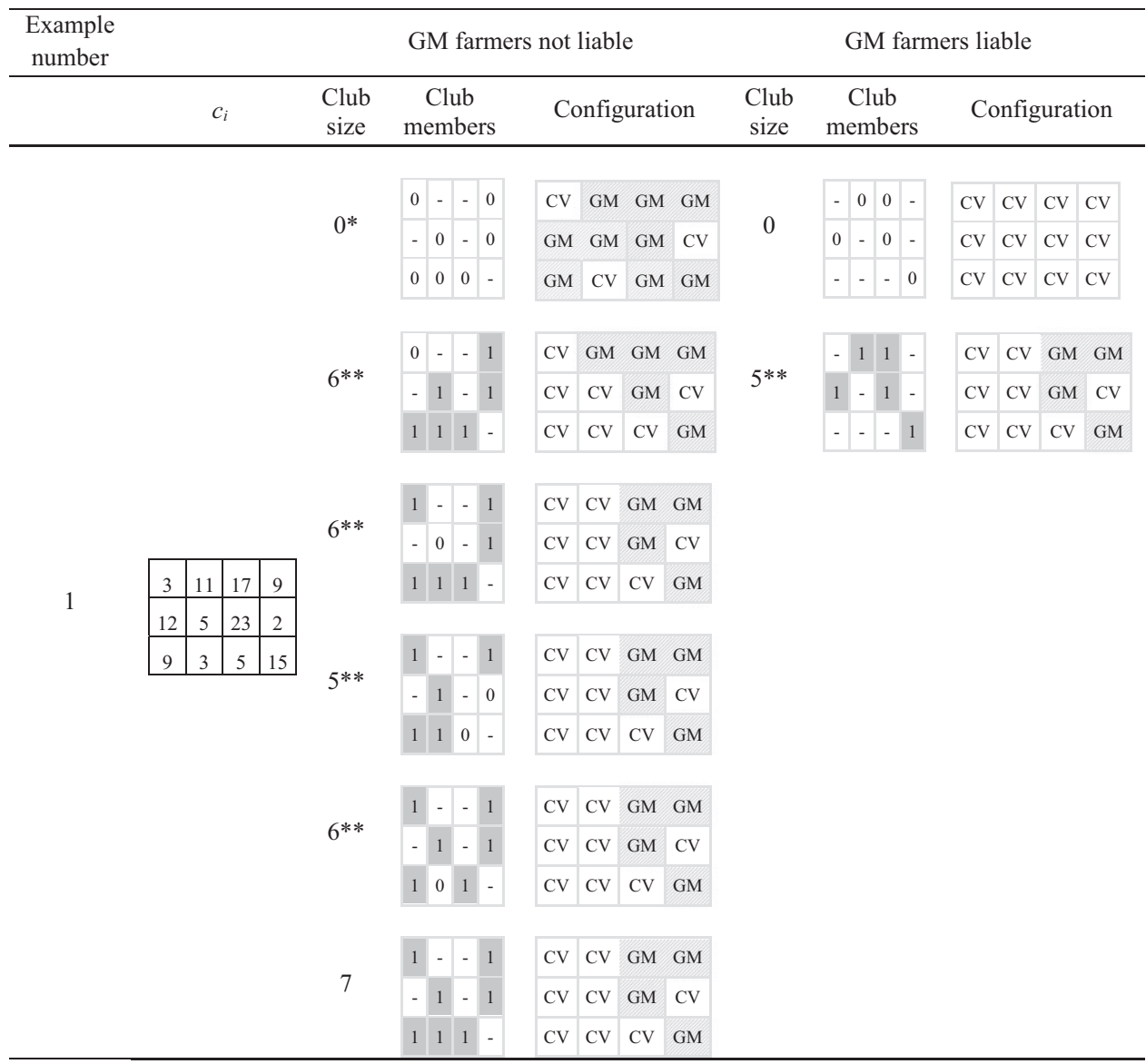

Figure 1. Club formation in a grid

Note: Two example draws are presented. The first column lists the number of the example draw. The second column lists the $c_{i}$ of each farmer. Each square represents a club. In the figure only the clubs that are fully stable as well as the Nash equilibrium (club size 0) and the largest club (the last square) are shown. Club members are marked in grey and labelled 1 , non-members are left blank and labelled 0 . The members addressed through Coasean bargaining are labelled with (-) and are not accounted for in club size. Internally stable clubs are marked with *, fully stable clubs with $* *$. The configuration shows the corresponding cultivation decisions by the club and the non-members. GM cultivation is marked hatched and labelled GM, non-GM cultivation left blank and labelled CV. If it is in the interest of the club, a club member (marked with 1) may continue to cultivate the variety that the club tries to address in its Coasean bargaining, that is, a member of a GM-free club may continue to cultivate GM and vice versa.

because free-riding makes forming large clubs harder. The reason for this movement is that with higher price premiums the small GM-free clubs have a larger buying power, and larger clubs are unnecessary to reach the efficient outcome. Similarly, the GM-only clubs have less buying power, and need larger clubs to reach an efficient outcome, but large clubs are hard to form. 


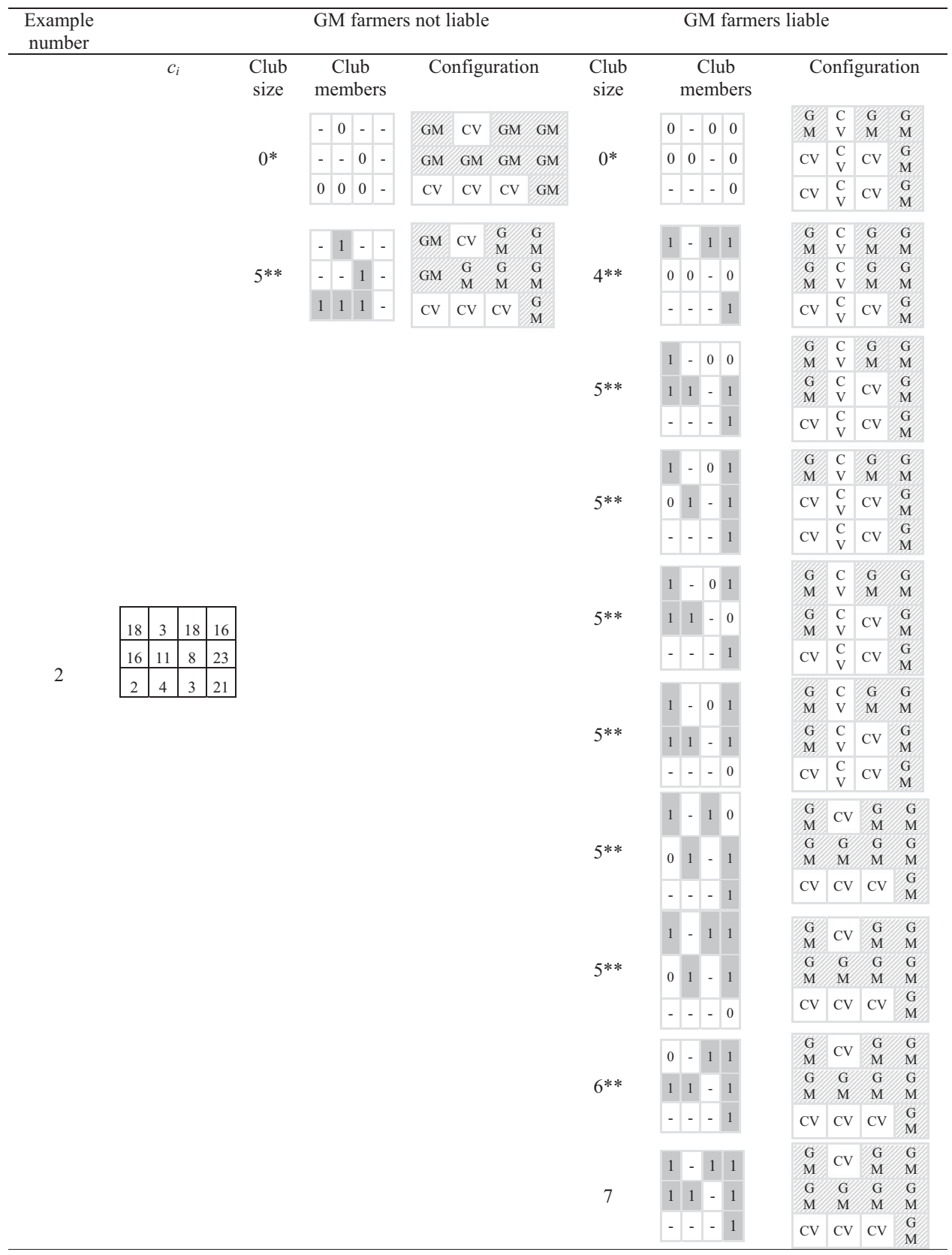

Figure 1. Continued.

The efficiency gains are usually larger when GM farmers are liable than when they are not liable, except for the setting that involves the largest maximum number of club members. Consequently, when GM farmers are liable the difference between the Nash equilibrium without negotiations and the efficient configuration is larger, and there are larger potential benefits for clubs to realise. However, realising all potential benefits by the clubs is difficult. The tables show that, with exception of the setting where 
the maximum number of club members is two, clubs are never able to fully close the gap. This is a result of free-riding: although it would be in the collective interest of the group for all farmers to join and participate in buying out other farmers, it is not in the individual interest of some of these farmers to join. Consequently, clubs that can solve the externality problem completely are not stable and smaller clubs form, which realise only a part of the potential benefits. Although some smaller stable clubs are also able to achieve an efficient configuration this does not hold for all of them (see also Figure 1).

The efficiency gains increase when the maximum number of club members increases because in the Nash equilibrium without negotiations there are more farmers cultivating the crop type that has the property rights. Many of these farmers would switch or revert in an efficient configuration. When GM farmers are liable, the efficiency gains decrease when the maximum number of club members becomes eight. The reason is that there are relatively few non-GM farmers to compensate.

Although clubs consisting of the maximum number of club members have a relatively large probability of being stable this probability declines steadily as the maximum number of club members increases (Tables 2 and 3). Clubs involving the maximum number of club members have an especially low probability of being stable once the maximum number of club members reaches eight when GM farmers are not liable and six when they are liable (Tables 2 and 3). In part this is mitigated by an increase in the probability of stability for smaller clubs. Although smaller clubs can sometimes reach an efficient allocation, it is clear from the closing the gap index that they do not always succeed in doing so. The larger clubs are not stable because an increasing number of potential club members implies there are more potential freeriders as well as more possible clubs that potential members could free-ride on. This in turn increases the claims of the free-riders and decreases stability.

Still, even though clubs are not able to realise the full gain, they do realise a sizeable part of the gain. What the smaller clubs often do achieve is solving a local externality, that is, an externality involving their direct neighbours. This can also be observed in Figure 1, for instance in example 1 when GM farmers are not liable and in example 2, when GM farmers are liable. Smaller clubs are able to realise the full potential efficiency gain when the maximum number of club members is small, but this typically means that the gain is also small.

Although we have not explicitly modelled the ex-ante costs of regulation we can infer some of their effects through the model. If GM farmers are not liable, the costs of ex-ante coexistence measures are shouldered by the non-GM farmers. Ceteris paribus, this means that their $c_{i}$ increases. In contrast, if GM farmers are liable they have to shoulder the costs, meaning that $c_{i}$ decreases as the incremental costs of farming non-GM crops decreases. In order to investigate the effect of ex-ante costs we look at the effect of the average $c_{i}$ for a fixed maximum number of club members on the efficiency gain and closing the gap. The effects for six players are presented in Table 4.

In Table 4 we observe the following: when GM farmers are not liable, the introduction of ex-ante costs increases the average $c_{i}$. Such an increase in $c_{i}$ makes GM farming relatively more attractive. Therefore, in the efficient configuration more farmers cultivate GM, and as the Nash equilibrium without negations favours GM cultivation as well, the difference between these two allocations becomes smaller, decreasing the efficiency gain. When GM farmers are liable the introduction of ex-ante coexistence costs decreases the average $c_{i}$, making non-GM farming more attractive in both the Nash equilibrium without negations and the efficient configuration, again decreasing the 
Table 4

Effect of ex-ante costs in a grid

\begin{tabular}{|c|c|c|c|c|c|c|c|}
\hline \multicolumn{4}{|c|}{ GM farmers not liable } & \multicolumn{4}{|c|}{ GM farmers liable } \\
\hline Average $c_{i}$ & $\begin{array}{l}\text { Efficiency } \\
\text { gain } \bar{\Omega}\end{array}$ & $\begin{array}{l}\text { Closing the } \\
\text { gap } \bar{\Gamma}\end{array}$ & $\begin{array}{l}\text { Number } \\
\text { of draws }\end{array}$ & Average $c_{i}$ & $\begin{array}{l}\text { Efficiency } \\
\text { gain } \bar{\Omega}\end{array}$ & $\begin{array}{l}\text { Closing the } \\
\text { gap } \bar{\Gamma}\end{array}$ & $\begin{array}{l}\text { Number } \\
\text { of draws }\end{array}$ \\
\hline$<9$ & $0.49 \%$ & $78.30 \%$ & 39 & $>13.5$ & $0.97 \%$ & $80.18 \%$ & 432 \\
\hline $9-10.5$ & $0.14 \%$ & $81.37 \%$ & 1,145 & $12-13.5$ & $0.83 \%$ & $79.47 \%$ & 2,939 \\
\hline $10.5-12$ & $0.07 \%$ & $84.78 \%$ & 4,692 & $10.5-12$ & $0.73 \%$ & $81.71 \%$ & 3,919 \\
\hline $12-13.5$ & $0.03 \%$ & $89.39 \%$ & 3,326 & $9-10.5$ & $0.40 \%$ & $83.69 \%$ & 1,074 \\
\hline$>13.5$ & $0.01 \%$ & $91.14 \%$ & 435 & $<9$ & $0.04 \%$ & $92.09 \%$ & 44 \\
\hline
\end{tabular}

Note: Maximum number of club members $n=6$ for both liability regimes.

efficiency gain. In addition, we observe that the smaller the efficiency gain, the more the clubs are able to realise this gain.

In total, these findings on ex-ante coexistence costs provide us with a mixed message for clubs. On the one hand, clubs introduce flexibility and lower ex-ante coexistence costs. This drives up the difference between the Nash equilibrium and the efficient configuration, increasing the potential gains from co-operation. However, this in turn reduces the stability of the clubs, and less of the potential gain is realised by these clubs due to free-riding.

\section{Discussion and Conclusions}

In this article we compare the efficiency of land allocation according to the Nash equilibrium, with the efficient allocation of land under two property rights systems and several liability. We further investigated the stability of clubs that form to mitigate the externality caused by the adventitious presence of GM crops under different property rights regimes. Using a simple farmer decision model combined with the notions of stability that are generally used in the literature of international environmental agreements, we derive the prospects for clubs under these different liability regimes.

We find that the Nash equilibrium without negotiation can already establish an efficient configuration. The differences in efficiency gain between the efficient allocation of land and the Nash equilibrium are less than 5\% at the maximum in both cases. Although our model shows slightly larger gains if GM farmers are liable, given the relative size the differences between the two property rights systems can thus be considered negligible. These results have important implications for the debate on coexistence. First, the allocation of property rights does not result in substantial differences with respect to the efficiency of allocating land, that is, neither the EU where the property right is with the non-GM farmer, nor the US system where the property right is with the GM farmer, makes a difference from an economic perspective. Second, having a coexistence policy that is based on ex-post several liability such as currently in the US, where the property right is more with the GM farmer, and Spain where the property right is more with the non-GM farmer and farmers are free to choose whether they like to cultivate GM crops or not, both result in an almost efficient allocation of land. This might explain why we observe almost no legal disputes between GM and non-GM farmers. This result is further supported when we compare our model set-up with real landscapes. We have considered a plain with no landscape 
structures such as roads, villages, hedges and trees. Those landscape structures act as additional pollen barriers and reduce the diffusion of pollen more than as assumed in our model.

In addition clubs very often realise a large part of the potential gain, albeit not always. These findings are in line those of Furtan et al. (2007) who investigate the possibility that organic farmers form a club and buy out neighbouring GM farmers to act as a buffer zone. They find this to be an economically feasible solution. However, they only investigate whether or not the club can compensate the reverting farmers, they do not consider the outside option payoff of the farmers in the club, or free-riding. Our article adds an extra dimension to their results: the clubs they report could form, but farmers do not necessarily have an incentive to stay in such clubs. Nevertheless, our results confirm theirs that the compensation principle holds.

The finding that club formation can realise a large part of the potential gain is in contrast with the existing literature that uses very different models but the same concepts of stability and stability likelihood, for example in fisheries and climate change (see e.g. Dellink et al., 2008; Pintassilgo et al., 2010). There are three potentially interacting reasons for the positive result about GM (or GM-free) clubs.

First of all it may be due to the relatively low potential efficiency gains. In the climate (Barrett, 1994) and the fisheries literature (Pintassilgo et al., 2010), co-operation becomes more difficult when the gains increase, and becomes easier when the gains are small. This, in turn, is due to the free-riding effect. Large gains from cooperation imply that there are large free-riding incentives. The opposite is true when gains are small. A second reason for the club results is the functional form of the objective functions chosen in the model. Karp and Simon (2013) have shown that this particularly affects stability. A third reason is the non-linear probability effect that causes decreasing marginal costs of switching from non-GM to GM crops, once others have switched. This allows for economies of scale.

Although we perform some comparative statics regarding coexistence costs, we do not consider the effects of further regulations such as minimum distance requirements in our article. It has been shown that these regulations can affect farmers' decisions to cultivate GM or non-GM crops via the domino effect (Groeneveld et al., 2013). When regulations raise coexistence costs, clubs may offer some flexibility to decrease the costs again, but as shown in the results of the simulations, whether or not clubs are able to realise the full gains remains to be seen. The model results presented here offer grounds for scepticism, but as Skevas et al. (2010) show it is possible in reality to have a club that realises the full gain. Nevertheless, our results show, without additional coexistence regulations, efficient allocation and product differentiation can be achieved. This is not uncommon in crop production as Kalaitzandonakes and Magnier (2016) and Pearsall (2016) have pointed out and raises further questions about the economic benefits of coexistence regulations found in many EU Member States. Our results suggest many of those (see, for example, Beckmann et al., 2014, for an overview) increase costs without generating economic benefits.

Our particular model has a few drawbacks. One is that we consider only the formation of a single club. In certain cases multiple clubs may form. However, we have also shown that in certain cases the externalities can be mitigated by the formation of a single club, in which case there is no reason to form multiple clubs. We also do not consider the possibility of multiple fields, which would give farmers more flexibility, and the effects of adventitious presence would probably be less severe. 
A further drawback is that we do not consider price effects and cannot draw conclusions about the overall welfare implications. However, our results will remain qualitatively the same if we include the demand side as this affects prices, which have been considered in the model. Finally, the model itself is static and, as such, dynamic incentives are not considered. Thus it is assumed that bought-out farmers actually stick to their decision and do not cheat. This is less of a problem where a non-GM farmer becomes a GM farmer. In the case where a GM farmer becomes a non-GM farmer, this might be different. Even though we did not consider dynamic aspects explicitly, cheating would not be economically efficient in the long run. One can justify this assumption in this context with an assumption of enforceable contracts. Future possible extensions of the model thus include equilibrium effects in general and dynamic formulations with possible enforcement issues. Further, considering the almost efficient allocation under the Nash equilibrium, we expect this will have only minor effects on the results.

In future research it is important to address two other important topics: first, the influence of spatial correlation and second, the effect of using alternative probabilitydistance functions. Spatial correlation may apply to the additional cost parameter. This parameter is driven by many factors, but a number of the agroecological conditions are likely to be spatially correlated. This means that potential GM farmers and non-GM farmers are more likely to be clustered in the landscape anyhow. This in turn would reduce the probability of adventitious presence. Similarly, neighbouring farmers often face similar social norms, share societal values, and in case they rent the land, have the same landowner. These factors are likely to make the negotiation easier, and bring down the transaction costs of the clubs (e.g. Venus et al., 2017). We therefore hypothesise that spatial correlation would make the formation of clubs easier.

We used a simple exponential function to describe the probability of adventitious presence. However, a number of functional forms have been used in the literature, for example, Bivariate student (Clark, 1998), Compound exponential (Damgaard and Kjellsson, 2005), or Normal inverse Gaussian (Klein et al., 2003). The main difference between these forms is in the dispersal distance and the fatness of their tails. An increase in either of these two parameters would increase the probability of adventitious presence.

We conclude there is scope for the voluntary formation of clubs that will result in either GM-free zones or GM-only zones, depending on who has the property rights, and that these clubs will usually be large but they are not always necessary to reach an efficient allocation.

\section{Supporting Information}

Additional Supporting Information may be found in the online version of this article:

Appendix S1: Proofs.

Appendix S2: Information on probabilities.

Appendix S3: Results for a line.

Appendix S4: Stability results when the price premium is $15 \%$.

\section{References}

Ansink, E. and Bouma, J. 'Effective support for community resource management', Forest Policy and Economics, Vol. 37, (2013) pp. 94-103. 
Barrett, S. 'Self-enforcing international environmental agreements', Oxford Economic Papers, Vol. 46(Suppl 1), (1994) pp. 878-894.

Barrett, S. 'International cooperation for sale', European Economic Review, Vol. 45, (2001) pp. $1835-1850$.

Beckmann, V. and Wesseler, J. 'Spatial dimension of externalities and the Coase theorem: Implications for co-existence of transgenic crops', in W. Heijman (ed.), Regional Externalities (Berlin Heidelberg: Springer Verlag, 2007, pp. 215-235).

Beckmann, V., Soregaroli, C. and Wesseler, J. 'Ex-ante regulation and ex-post liability under uncertainty and irreversibility: Governing the coexistence of GM crops', Economics: The Open-Access, Open Assessment E-Journal, Vol. 4, (2010) pp. 1-33.

Beckmann, V., Soregaroli, C. and Wesseler, J. 'Coexistence of genetically modified (GM) and non-modified (non GM) crops: Are the two main property rights regimes equivalent with respect to the coexistence value?' in C. Carter, G. Moschini and I.M. Sheldon (eds.), Genetically Modified Food and Global Welfare (Bingley: Emerald Group Publishing, 2011, pp. 201224).

Beckmann, V., Soregaroli, C. and Wesseler, J. 'Coexistence', in: D. Castle, P. Phillips and S. Smyth (eds.), Handbook on Agriculture, Biotechnology and Development. (Cheltenham: Edward Elgar, 2014,pp. 372-391.

Clark, J. S. 'Why trees migrate so fast: Confronting theory with dispersal biology and the paleorecord', The American Naturalist, Vol. 152, (1998) pp. 204-224.

Coase, R. H. 'The problem of social cost', Journal of Law and Economics, Vol. 3, (1960) pp. 1-44.

Consmüller, N., Beckmann, V. and Petrick, M. 'Identifying driving factors for the establishment of cooperative GMO-free zones in Germany', International Association of Agricultural Economists 2012 Conference (Foz do Iguacu, Brazil, 2012).

Damgaard, C. and Kjellsson, G. 'Gene flow of oilseed rape (Brassica napus) according to isolation distance and buffer zone', Agriculture, Ecosystems \& Environment, Vol. 108, (2005) pp. 291-301.

D’Aspremont, C., Jacquemin, A., Gabszewicz, J. J. and Weymark, J. A. 'On the stability of collusive price leadership', The Canadian Journal of Economics, Vol. 16, (1983) pp. 17-25.

Dellink, R., Finus, M. and Olieman, N. 'The stability likelihood of an international climate agreement', Environmental and Resource Economics, Vol. 39, (2008) pp. 357-377.

European Commission. 'Commission recommendation of 13 July 2010 on guidelines for the development of national co-existence measures to avoid the unintended presence of GMOs in conventional and organic crops', Official Journal of the European Union, Vol. C 200, (2010) pp. $1-5$.

Finus, M. 'Stability and design of international environmental agreements: The case of transboundary pollution', International Yearbook of Environmental and Resource Economics, Vol. 4, (2003) pp. 82-158.

Foster, M. 'Evidence of price premiums for non-GM grains in world markets', AARES Conference 2010 (Adelaide, 2010).

Furtan, W. H., Güzel, A. and Weseen, A. S. 'Landscape clubs: Co-existence of genetically modified and organic crops', Canadian Journal of Agricultural Economics, Vol. 55, (2007) pp. 185195.

Groeneveld, R. A., Wesseler, J. and Berentsen, P. B. M. 'Dominos in the dairy: An analysis of transgenic maize in Dutch dairy farming', Ecological Economics, Vol. 86, (2013) pp. 107-116.

Herring, R. J. 'Opposition to transgenic technologies: Ideology, interests and collective action frames', Nature Reviews Genetics, Vol. 9, (2008) pp. 458-463.

Kalaitzandonakes, N. and Magnier, A. 'What can we learn about coexistence from commercial non-GM programs in the US?' in N. Kalaitzandonakes, P. W. B. Phillips, J. Wesseler and S. J. Smyth (eds.), The Coexistence of Genetically Modified, Organic and Conventional Foods: Government Policies and Market Practices (New York, NY: Springer New York, 2016, pp. 95-102). 
Karp, L. and Simon, L. 'Participation games and international environmental agreements: A non-parametric model', Journal of Environmental Economics and Management, Vol. 65, (2013) pp. 326-344.

Klein, E. K., Lavigne, C., Foueillassar, X., Gouyon, P.-H. and Larédo, C. 'Corn pollen dispersal: Quasi-mechanistic models and field experiments', Ecological Monographs, Vol. 73, (2003) pp. 131-150.

Koch, B. A. Economic Loss Caused by Genetically Modified Organisms: Liability and Redress for the Adventitious Presence of GMOs in non-GM Crops. Vienna: Springer Vienna, 2008.

McEvoy, M. Organic 101: Can GMOs Be Used in Organic Products? (USDA Blog, 2013). Available at: http://blogs.usda.gov/2013/05/17/organic-101-can-gmos-be-used-in-organic-produc ts/ (last accessed 14 September 2015).

Moschini, G. 'In medio stat virtus: Coexistence policies for GM and non-GM production in spatial equilibrium', European Review of Agricultural Economics, Vol. 42, (2015) pp. 851-874.

Olieman, N. J. and Hendrix, E. M. T. 'Stability likelihood of coalitions in a two-stage cartel game: An estimation method', European Journal of Operational Research, Vol. 174, (2006) pp. 333-348.

Pearsall, D. 'GM crop coexistence in practice: Delivering real choices for farmers and consumers', EuroChoices, Vol. 15, (2016) pp. 12-16.

Pintassilgo, P., Finus, M., Lindroos, M. and Munro, G. 'Stability and success of regional fisheries management organizations', Environmental and Resource Economics, Vol. 46, (2010) pp. 377-402.

Qaim, M. 'The economics of genetically modified crops', Annual Review of Resource Economics, Vol. 1, (2009) pp. 665-694.

Scatasta, S., Wesseler, J. and Hobbs, J. 'Differentiating the consumer benefits from labeling of GM food products', Agricultural Economics, Vol. 37, (2007) pp. 237-242.

Seabright, P. 'Managing local commons: Theoretical issues in incentive design', The Journal of Economic Perspectives, Vol. 7, (1993) pp. 113-134.

Skevas, T., Fevereiro, P. and Wesseler, J. 'Coexistence regulations and agriculture production: A case study of five Bt maize producers in Portugal', Ecological Economics, Vol. 69, (2010) pp. 2402-2408.

Smart, R., Blum, M. and Wesseler, J. 'EU member states' voting for authorizing genetically engineered crops: A regulatory gridlock', German Journal of Agricultural Economics, Vol. 64, (2015) pp. 244-262.

US Department of Agriculture. Coexistence Factsheets (United States Department of Agriculture, 2015). Available at: http://www.usda.gov/wps/portal/usda/usdahome?contentidonly = true\&contentid = coexistence-factsheets.xml (last accessed 9 May 2016).

Venus, T. J., Dillen, K., Punt, M. J. and Wesseler, J. H. H. 'The costs of coexistence measures for genetically modified maize in Germany', Journal of Agricultural Economics, Vol. 68, (2017) pp. 407-426.

Weikard, H.-P. 'Cartel stability under an optimal sharing rule', The Manchester School, Vol. 77, (2009) pp. 575-593.

Wesseler, J. 'Biotechnologies and agrifood strategies: Opportunities, threats and economic implications', Bio-Based and Applied Economics, Vol. 3, (2014) pp. 187-204. 